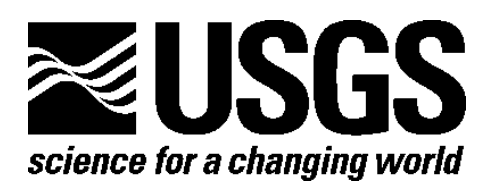

\title{
Assembling Probabilistic Performance Parameters of Shale-Gas Wells
}

\author{
By Troy Cook and Ronald R. Charpentier
}

Open-File Report 2010-1138 


\section{U.S. Department of the Interior \\ KEN SALAZAR, Secretary}

\section{U.S. Geological Survey \\ Marcia K. McNutt, Director}

U.S. Geological Survey, Reston, Virginia: 2010

For product and ordering information:

World Wide Web: http://www.usgs.gov/pubprod

Telephone: 1-888-ASK-USGS

For more information on the USGS—-the Federal source for science about the Earth,

its natural and living resources, natural hazards, and the environment:

World Wide Web: http://www.usgs.gov

Telephone: 1-888-ASK-USGS

Suggested citation:

Cook, Troy, and Charpentier, R.R., 2010, Assembling probabilistic performance parameters of shale-gas wells: U.S. Geological Survey Open-File Report 2010-1138, 17 p.

Any use of trade, product, or firm names is for descriptive purposes only and does not imply endorsement by the U.S. Government.

Although this report is in the public domain, permission must be secured from the individual copyright owners to reproduce any copyrighted material contained within this report. 


\section{‡USGS \\ science for a changing world}

\section{Assembling Probabilistic Performance Parameters of Shale-Gas Wells.}

Troy Cook, Ronald R. Charpentier Central Energy Resources Science Center U.S. Geological Survey 


\section{USGS Assessment Methods}

Well productivity estimates in USGS assessments from 1995 to present are based on studies that require decline curve fits and analysis to a large sample or to all wells within a particular assessment unit

\section{‡USGS}

An assessment unit is a mappable volume of rock within a total petroleum system that encompasses fields and wells that share similar geologic characteristics. 


\section{Advantages}

Captured components of a decline curve, such as initial production and decline rates, can be used to calculate derivative products - for example, estimated ultimate recovery (EUR)

\section{Disadvantages}

Time and labor intensive

‡USGS 


\section{Shale Gas EUR Input for USGS Assessments}

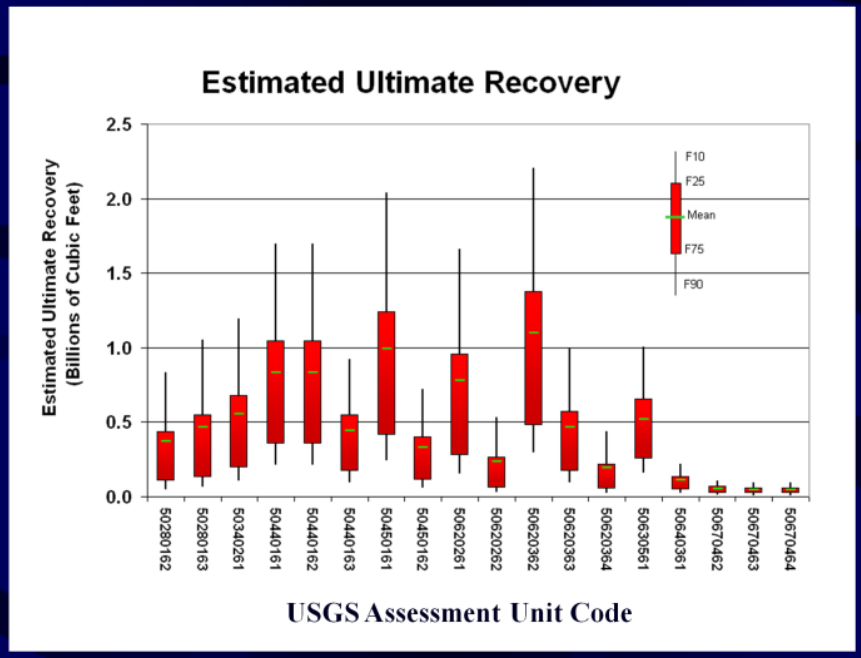

¿USGS

This figure was constructed using USGS shale-gas input parameters from the National Oil and Gas Assessment Project for shale-gas units during the past decade. X-axis labels designate the specific unit using the National Oil and Gas Assessment numbering system. 


\section{Data Analysis Goals}

- Provide more automation

- Make applicable to large or small data sets

- Produce readily understandable results and comparisons

- Maintain high degree of dependency on actual production data

- Incorporate multiple data types and streams

\section{₹USGS}




\section{Probabilistic Type Curves (PTC)}

- Can be created on nearly any size well group

- Results are displayed in the same general form as a regular type curve

- Automation allows creation and comparison between multiple well groups in a timely fashion

- Uncertainty in both decline rates and EUR is already built-in 


\section{Type Curve Construction}

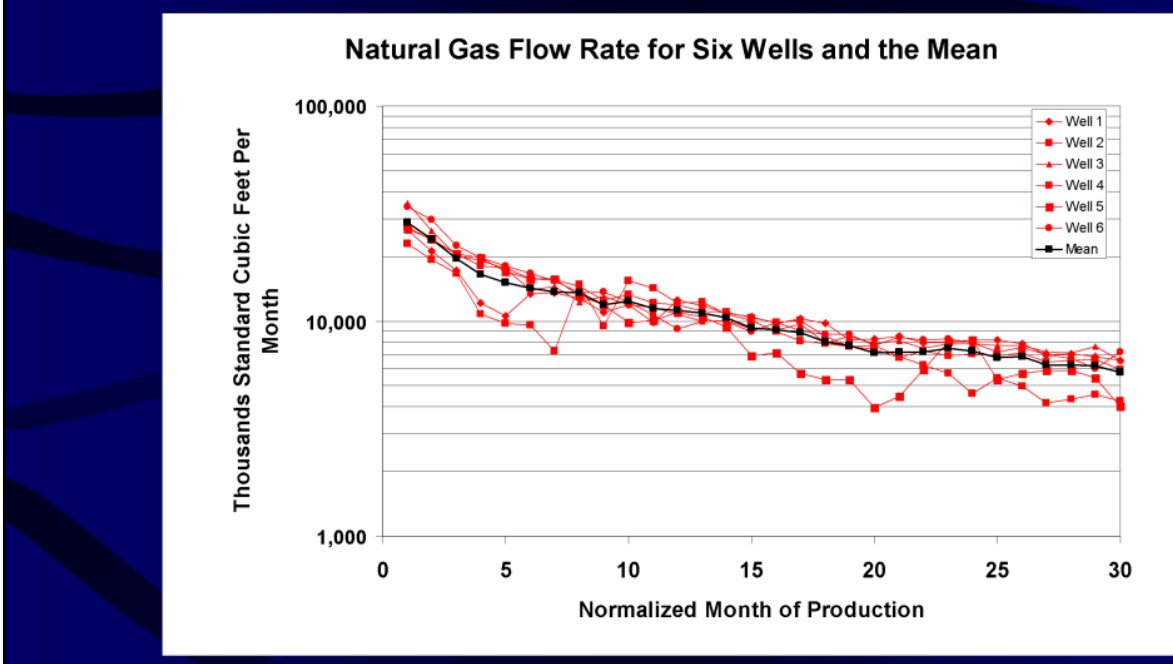

\section{\#USGS}

The first thirty months of natural gas production from six Barnett Shale vertical wells were normalized to the first full month of production for each well and then used to construct this figure. A central tendency (mean) of these six wells was included. 


\section{Forecasting a Type Curve}

\section{Mean Natural Gas Production Rate Curve Fit and Forecast}

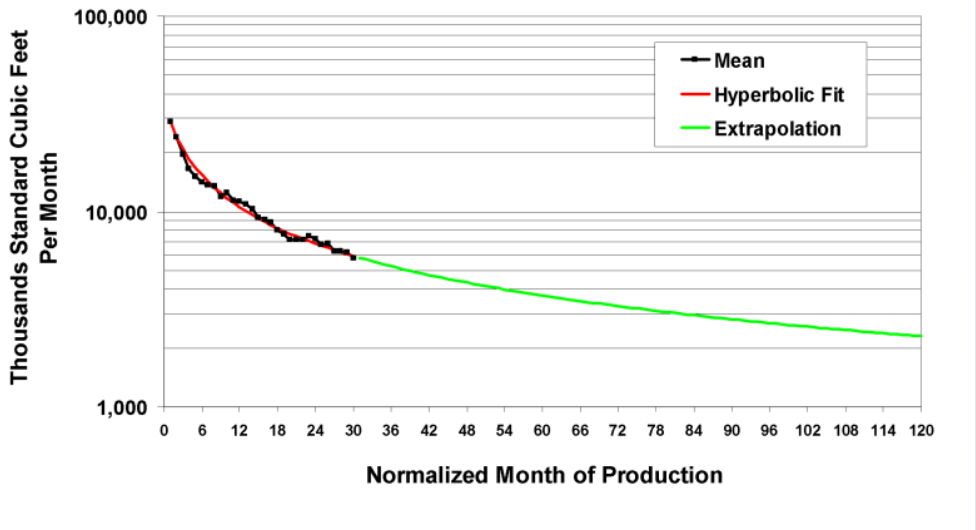

₹USGS

A hyperbolic decline curve was fitted to the mean production decline of the six Barnett Shale gas wells shown in the previous slide. This example demonstrates a calculation of estimated ultimate recovery based on a 90 month forecast of the expected decline. 


\section{Type Curve + "Anomaly"}

Natural Gas Production Rate for Seven Wells and the Mean of the First Six Wells

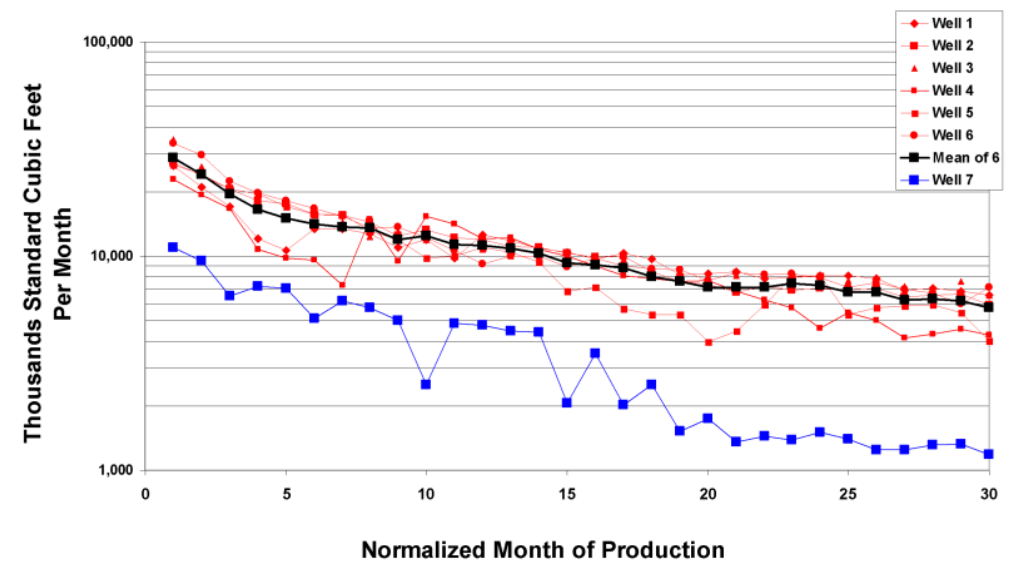

\#USGS

This slide demonstrates a common issue with type curves. The addition of an anomalous well, such as well 7 , can affect the validity of the type curve as well as any calculations performed. The decision to include, or exclude, the anomalous well is based on the professional judgment of the person constructing the type curve. This decision may be based on criteria other than trying to construct the most reasonable measure of central tendency. This slide is critical to explaining why a regular type curve may not be a reasonable construct for resource assessments. A resource assessor needs to understand the behavior of an entire group, and this includes wells that might otherwise be considered engineering or geologic failures. 


\section{Type Curve + "Anomaly"}

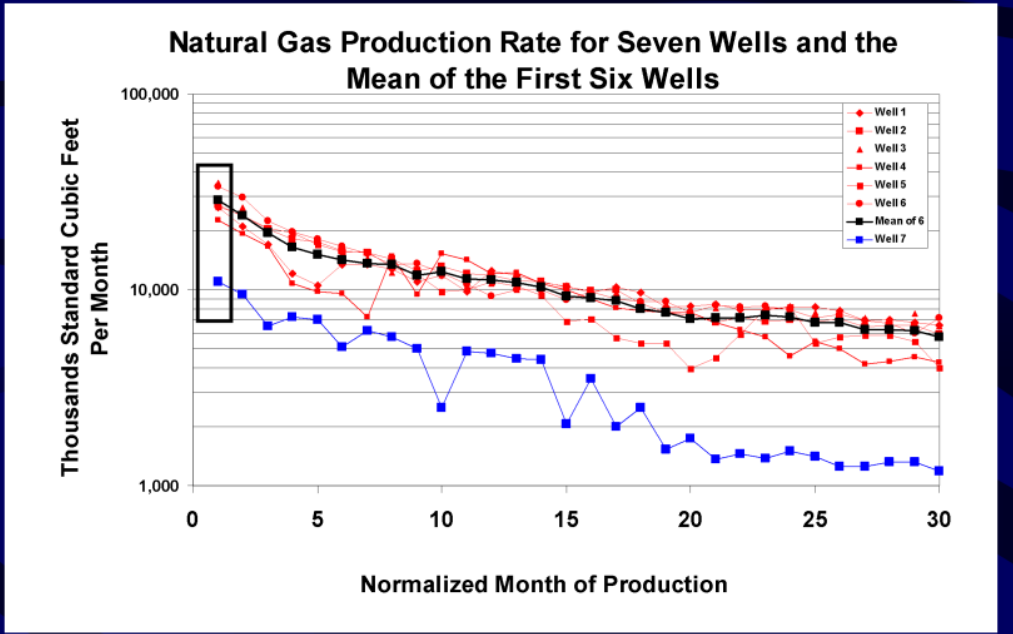

\section{\#USGS}

The boxed area designates the particular month chosen for a more detailed examination. 


\section{Single Month, Many Wells}

\section{First Month of Production for Fayetteville Shale Horizontal Wells}
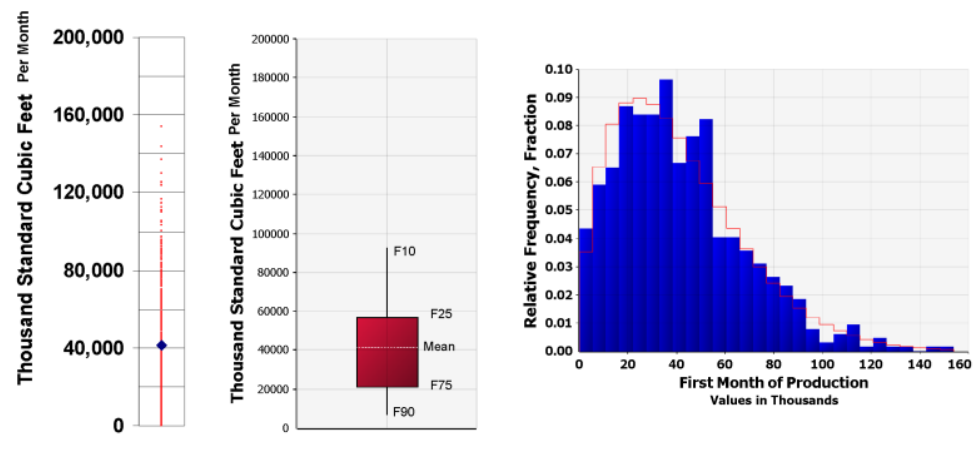

\section{₹USGS}

This figure has three different representations of the same monthly production data for the same group of wells. The far left example most closely resembles the prior slide where all data are plotted for a given month. The box-whisker plot and the histogram utilize the same information. A thin red line outlining the shape of the histogram is a best fit for the data using the Anderson-Darling test. 


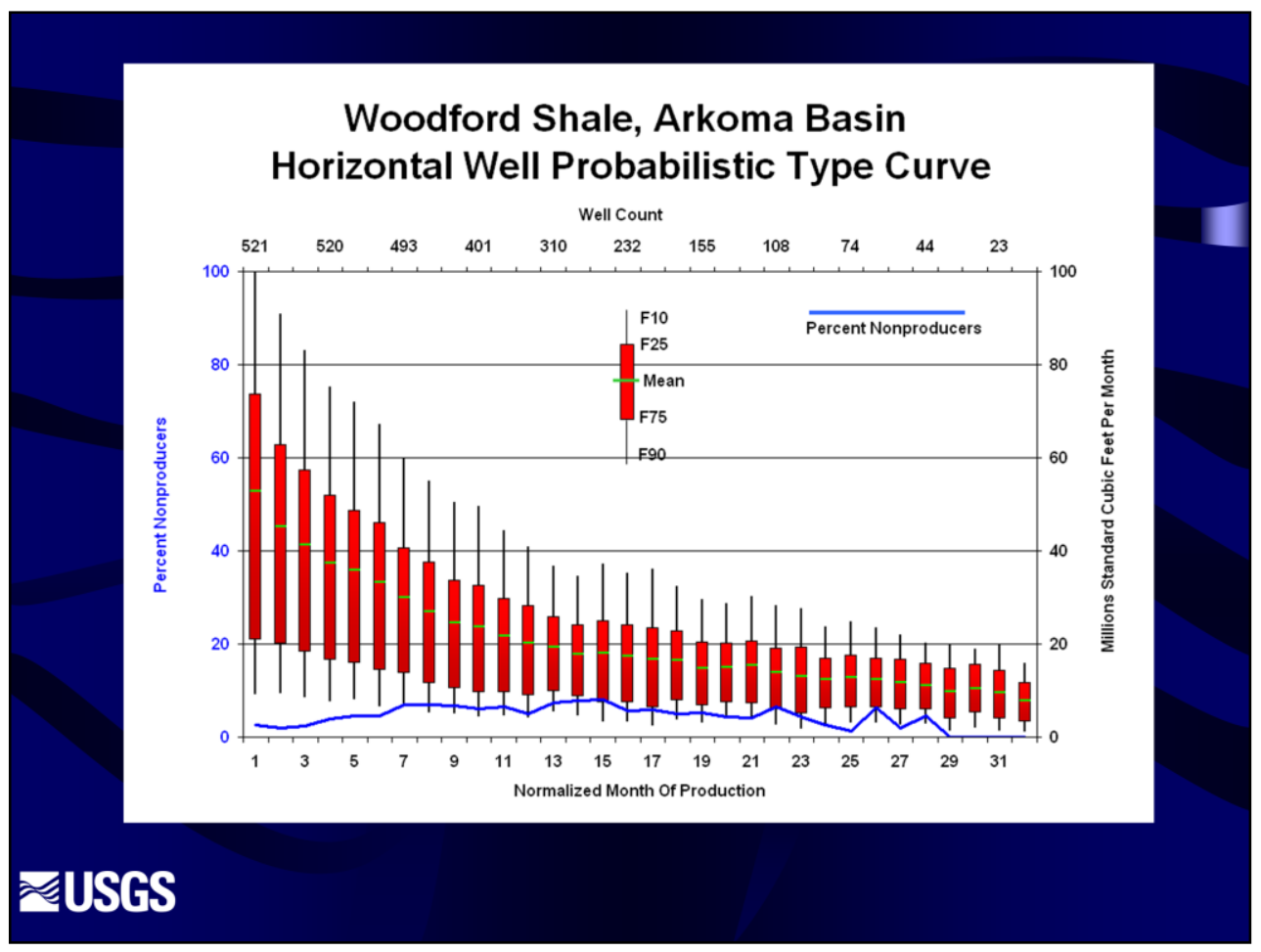

This slide contains a complete probabilistic type curve (PTC). Each boxwhisker plot represents sequential single months of normalized production data for a group of wells. Additional information collected includes the data density in each box-whisker plot and the number of wells in each month that were not producing. From this graph one can calculate: (1) probabilistic estimates of decline rate between any two normalized months, (2) probabilistic estimates of ultimate recovery, and (3) economic potential. 


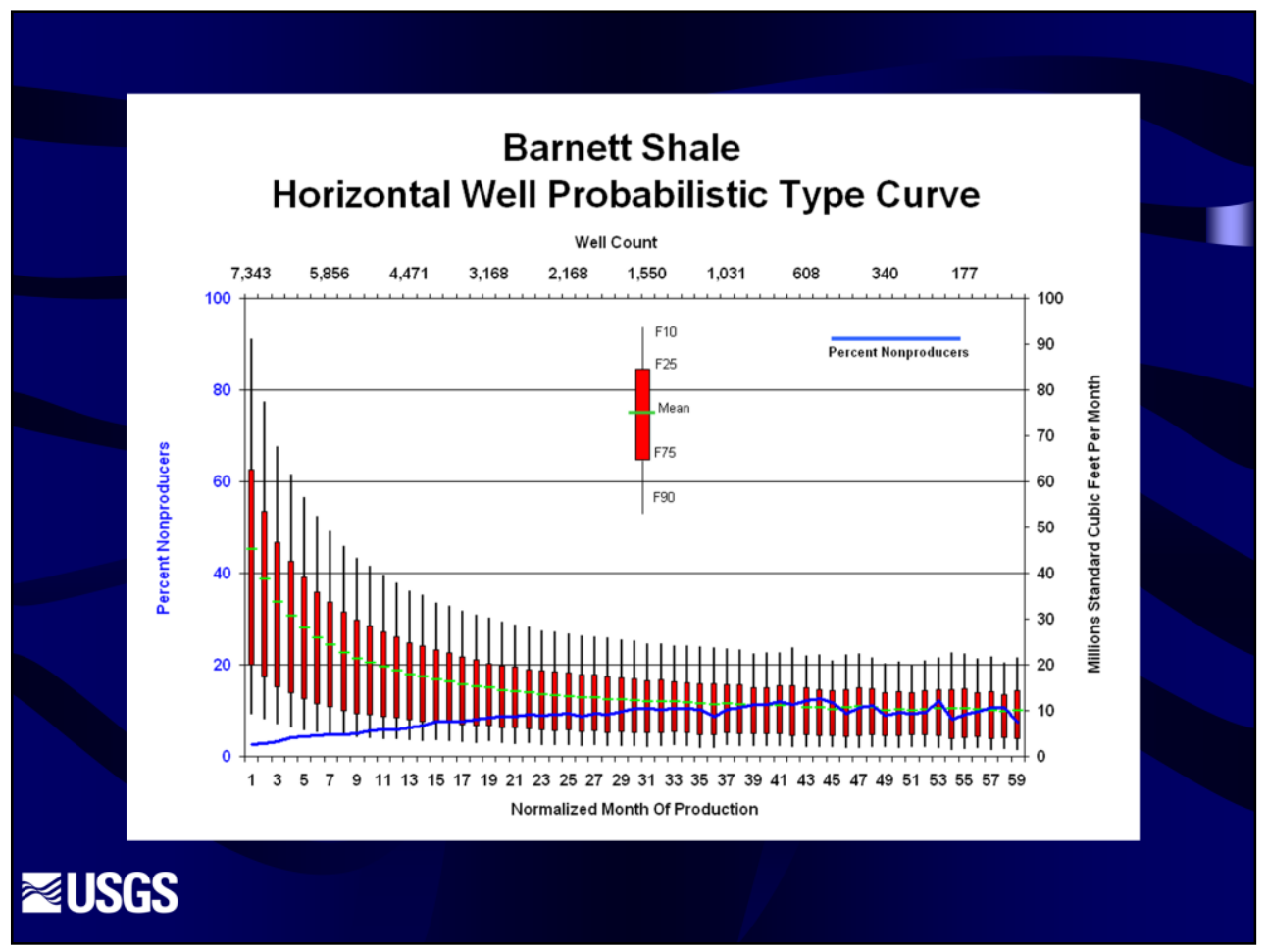




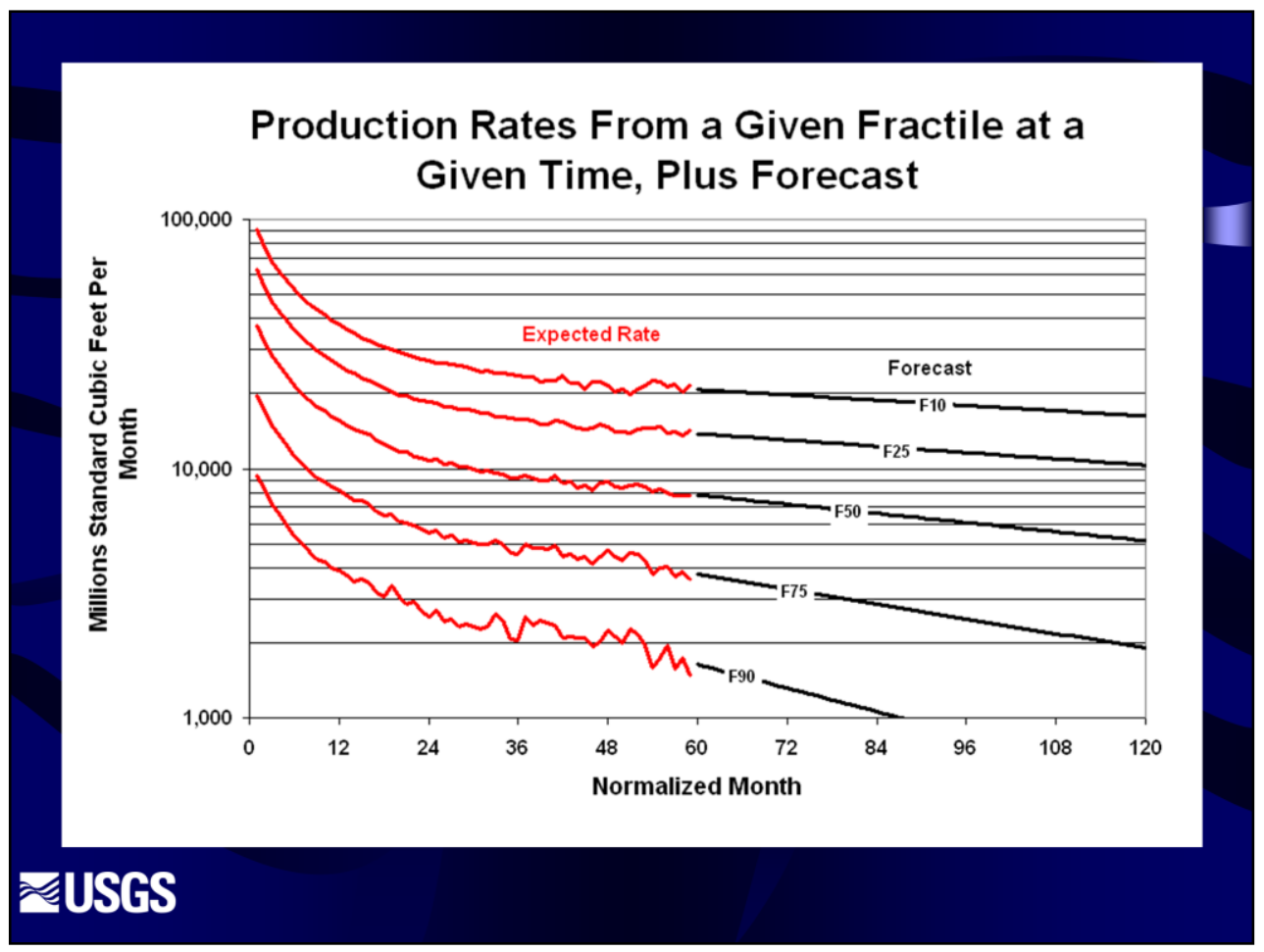

This figure demonstrates lines of perfect positive correlation (each line following the same fractile of probability through different density functions) for a particular probabilistic type curve. A best fit exponential, hyperbolic or mixed decline is then calculated and forecast through a given amount of time to create a single estimated ultimate recovery. A Monte Carlo simulator using these basic principles repeats the process thousands of times and creates a probabilistic estimated ultimate recovery. 


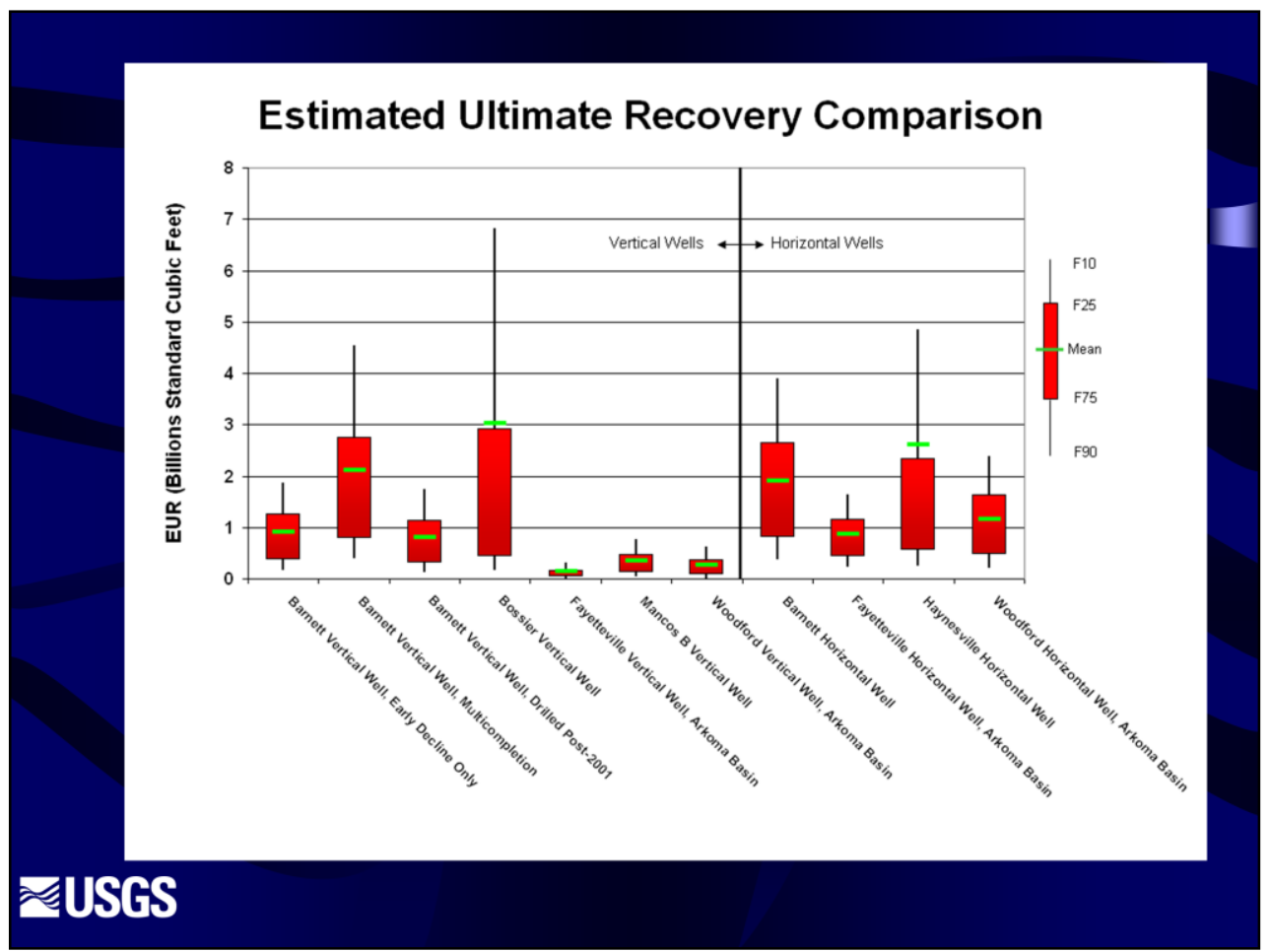

Each group in this figure was analyzed using its unique probabilistic type curve and the process described on the previous slide and forecast over a thirty year well lifespan. These estimated ultimate recoveries are not comparable to the input parameters within any evaluated National Oil and Gas Assessment Unit but were created during the course of testing the probabilistic type curve concept. 


\section{Final Thoughts}

- The PTC was designed for use within a resource context

- The PTC was designed to improve on the familiar format of a deterministic type curve by showing the full range of production possibilities for a given group of wells

- Additional information was added to make certain components, such as data density and nonproducing wells, more explicit

‡USGS 


\section{Current Progress}

Publications on the PTC results are in review and upon completion will be located at the following USGS National Oil and Gas Assessment link:

http://energy.cr.usgs.gov/oilgas/noga/methodology.html

\section{₹USGS}

